\title{
BUCKLING ANALYSIS OF STIFFENED PANEL FOR AIRCRAFT FUSELAGE
}

\author{
UDAY DEEPIKA. $A^{1} \&$ K. VEERANJANEYULU ${ }^{2}$ \\ ${ }^{I}$ Assistant Professor, Department of Aeronautical Engineering, MLR Institute of Technology, Hyderabad, Telangana, India \\ ${ }^{2}$ Associate Professor, Department of Aeronautical Engineering, MLR Institute of Technology, Hyderabad, Telangana, India
}

ABSTRACT
In the present work, structural analysis of stiffened panel for aircraft fuselage is performed for pure composites
and composite plates with isogrid and orthogrid using FEM. In the bulking analysis of the panel, the static analysis is
carried out under the specified loading and boundary conditions and results are extended to the buckling analysis. In the
buckling analysis of stiffened panel, the mode shapes are extracted and frequencies are tabulated. The material selected
for the analysis is carbon fiber, carbon fabric epoxy composite by precision contact lay-up. The fiber orientation for the
isogrid structure is $60^{\circ} / 30^{\circ}$ and for the orthogrid, the fiber orientation is $0^{0} / 90^{\circ}$. The analysis shows that the orthogrid
structure is better than the other panels. The inplane load bearing capacity of the orthogrid structured panel is more than
the isogrid panel structure. The weight of the orthogrid structured panel is less than the isogrid stiffened panel.
KEYWORDS: Structural Analysis, Epoxy Composite \& Stiffened Panel

Received: Dec 02, 2017; Accepted: Dec 23, 2017; Published: Feb 15, 2017; Paper Id.: IJMPERDFEB2018150

\section{INTRODUCTION}

Fuselage is a long hollow tube that carries payload and the equipment required for the sustainable flight. The aircraft fuselage is made up of aluminum rings and stiffeners to support a thin aluminum skin to reduce weight. An aluminum fuselage is typically constructed by the semi-monocoque method, which consists of longitudinal stringers, ring frames, and end rings as shown in Figure 1.1. A series of frames in the shape of the fuselage cross section are held in position on a rigid fixture. Aluminum ring frames are equally spaced over the length of the cylinder. The ring frames are joined with light-weight longitudinal elements called stringers. The ring frame and stringers are covered with a skin of sheet aluminum, which is attached by riveting or by bonding with special adhesives.

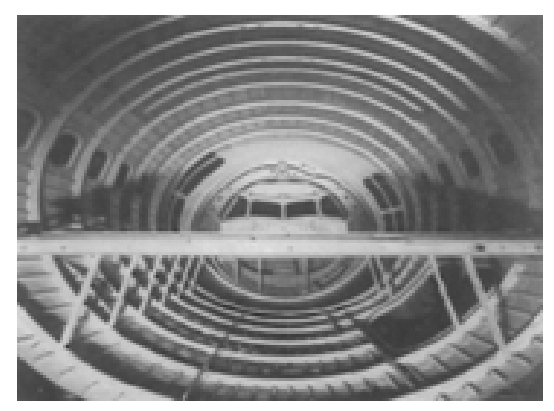

Figure 1.1: Fuselage Showing Frames, Stringers and Skin

\subsection{Fuselage Panel}

This is a simple structural analysis of a composite fuselage panel of a model airplane made of stringers, 
i.e. a stringer riveted to a skin panel [1]. The fuselage section is of uniform configuration along its length and its crosssectional area is defined to be a plate as shown. Figure 1 shows the whole panel and gives an idea of its location in a real aircraft. The considered stringers have a trapezoidal profile - they are also called Omega stringers. It is held fixed to the body of the airplane on one end and pinned at the other end. The panel and the associated super-stringers are made of composite layers, each of them being defined by an orientation and a thickness

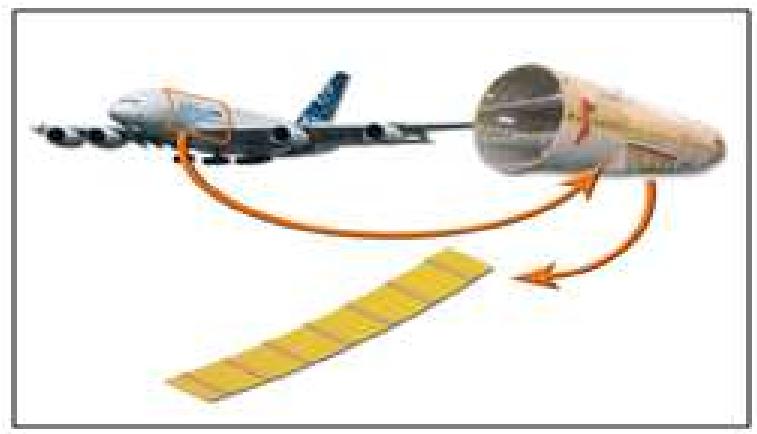

Figure 1.2: Fuselage Panel and Associated Model

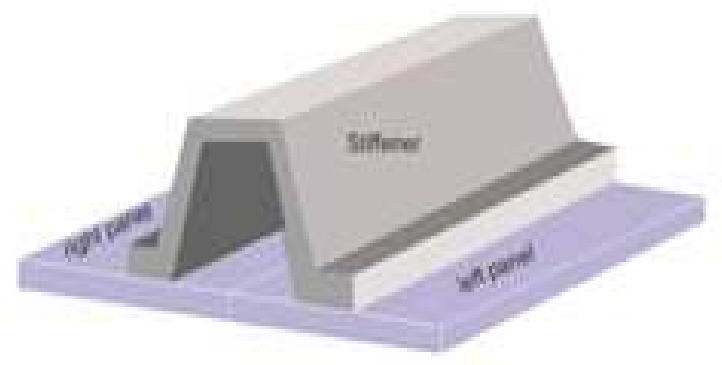

Figure 1.3: Omega Super-Stringer (Stringer Profile and Adjacent Skin Panels)

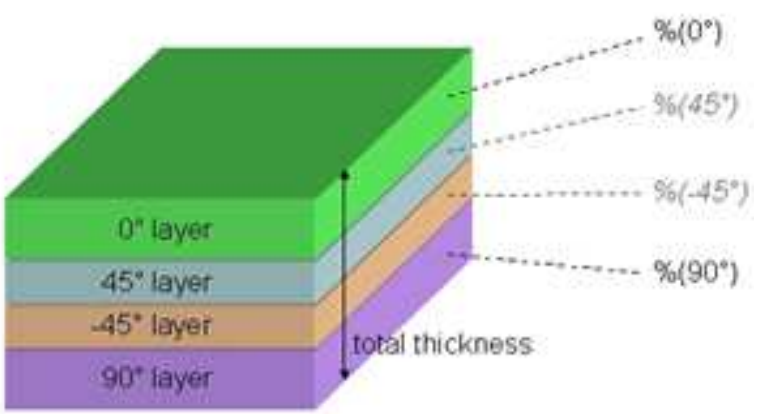

Figure 1.4: Laminated Composite Plate

While the fiber angle is restricted to take eleven discrete values $\left(90^{\circ}, 30^{\circ},-30^{\circ}, 30,-30,-30,30,-30,30\right.$ and $\left.90^{\circ}\right)$, the thickness may vary continuously between some predefined bounds, which were set to 0.5 and $15 \mathrm{~mm}$ in this case. The goal of our problem is to obtain Buckling behavior of given fuselage sections, where the first buckling loads is evaluated and corresponding mode shapes will be presented, and to find which comparing the result of each plate for its efficiency using finite element analysis method.

\subsection{Conventional Fuselage Loads}

The fuselage structure design should sustain the cyclic pressure loads due to cabin pressurization and De- 
pressurization, Bending, Shear, Torsional and fatigue loads. The fuselage should be designed for the strength, rigidity and fail life.

The direct stress distribution due to bending can be calculated

$$
\sigma_{z}=\frac{M_{x}\left(I_{y y} y-I_{x y} x\right)}{I_{x x} I_{y y}-I_{x y}^{2}}+\frac{M_{y}\left(I_{x x} x-I_{x y} y\right)}{I_{x x} I_{y y}-I^{2} x y}
$$

Where,

$\mathrm{M}_{\mathrm{x}}, \mathrm{M}_{\mathrm{y}}=$ Bending moment about $\mathrm{x}$ and $\mathrm{y}$ axis

$\mathrm{I}_{\mathrm{xx}}, \mathrm{I}_{\mathrm{yy}}, \mathrm{I}_{\mathrm{xy}}=$ Area moment of inertia.

The shear flow distribution due shear can be obtained as

$$
q_{s}=-\left(\frac{S_{x} I_{x x}-S_{y} I_{x y}}{I_{x x} I_{y y}-I_{x y}^{2}}\right) \sum_{r=1}^{n} B_{r} y_{r}-\left(\frac{S_{y} I_{y y}-S_{x} I_{x y}}{I_{x x} I_{y y}-I_{x y}^{2}}\right) \sum_{r=1}^{n} B_{r} x_{r}+q_{s, 0}
$$

Where,

Qs= Shear flow distribution

$\mathrm{Sx}, \mathrm{Sy}=$ Shear loads in $\mathrm{x}$ and $\mathrm{y}$ direction

Ixx,Iyy,Ixy= Moment of areas

$\mathrm{Xr}, \mathrm{Yr}=$ Center of twist at point $\mathrm{x}, \mathrm{y}$

$\mathrm{Br}=$ Cross-sectional area

The shear flow due to Torsion for single-cell closed-section beam can be obtained

$$
q=\frac{T}{2 A}
$$

where

$\mathrm{q}=$ Shear flow distribution due to applied torque

$\mathrm{T}=$ Applied torque

$\mathrm{A}=$ Area

\subsection{DESIGN OF STIFFENED FUSELAGE PANEL}

\section{Isentropic Material}

The panel of the fuselage section is made from the isotropic aluminum plate. The dimensions of the panel taken for the analysis is shown in the figure 2.1. 


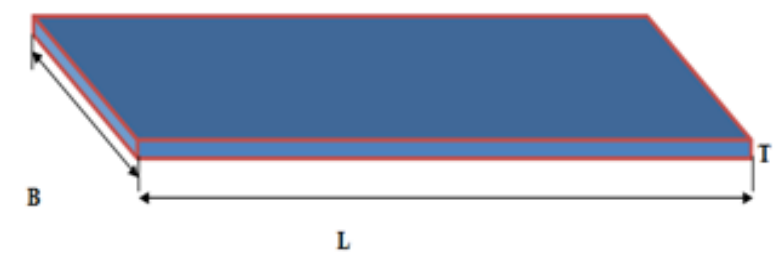

Figure2.1: Isotropic Plate

Table 1.1: Thickness of the Stiffened Panel

\begin{tabular}{|l|c|c|c|c|}
\hline \multicolumn{1}{|c|}{ Material Type } & $\begin{array}{c}\text { Skin Thickness } \\
(\mathbf{m m})\end{array}$ & $\begin{array}{c}\text { Stiffner } \\
\text { Height }\end{array}$ & $\begin{array}{c}\text { No of } \\
\text { Layers }\end{array}$ & Thickness \\
\hline Isotropic(aluminum) & 7 & - & - & $6.90 \mathrm{~mm}$ \\
\hline Pure composite & 5 & 15 & 10 & 13 \\
\hline Composite with isogrid & 5 & 15 & 10 & 20 \\
\hline Composite with orthogrid & 5 & 15 & 10 & 20 \\
\hline
\end{tabular}

\section{Thickness Calculation}

The plate is fixed at one end and hinged at other end as it is a long plate made up of isotropic material.

Given Data: $\mathrm{L}=800 \mathrm{~mm}$

$B=200 \mathrm{~mm}$

Operating load $=2$ tons

Factor of safety $=1.33$

Buckling factor $=$ design load $/$ Operating load

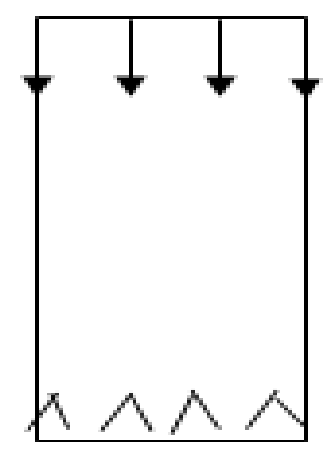

Figure2.2: Plate with Loads \& Constraints

Design load $=$ buckling factor $\times$ operating load

$$
\begin{aligned}
& =5 \times 2000 \times 9.81 \times 1.33 \\
& =130470 \mathrm{~N}
\end{aligned}
$$

Design load $(\mathrm{Pe})=130470 \mathrm{~N}$

The buckling load is obtained

$\mathrm{Pe}=\pi^{2} \mathrm{EI} / \mathrm{Le}^{2}$

$130470=\left(\pi^{2} \times 210 \times 10^{3} \times 150 \times \mathrm{T}^{3}\right) /\left(800^{2} /(\sqrt{ } 2)^{2} \times 12\right)$ 
$\mathrm{t}=6.90 \mathrm{~mm}($ approx $7 \mathrm{~mm})$

The thickness for a isotropic plate is $\mathbf{t}=\mathbf{7} \mathbf{~ m m}$

\section{Composite Plate}

The fuselage panel is made up composite material

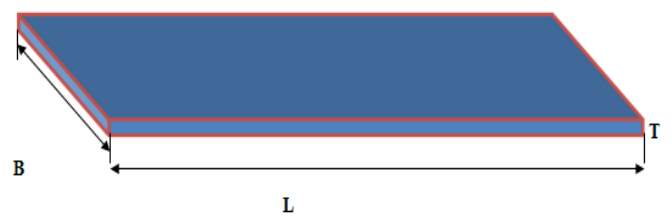

Figure2.3: Composite Plate

\section{Dimensions of Composite Plate}

Thickness of plate $=\mathrm{t}=13 \mathrm{~mm}$

\section{Thickness Calculation}

For a long plate with all sides clamped and loaded in the $\mathrm{x}$ - direction only, the buckling load per unit width can be estimated as

$\left.\mathrm{N}_{\mathrm{xCR}}=\left(\prod^{2} / \mathrm{b}^{2}\right)(4.6(\mathrm{D} 11 \mathrm{D} 22))^{1 / 2}+2.67 \mathrm{D} 12+5.33 \mathrm{D} 66\right)$

Substituting the value of constants

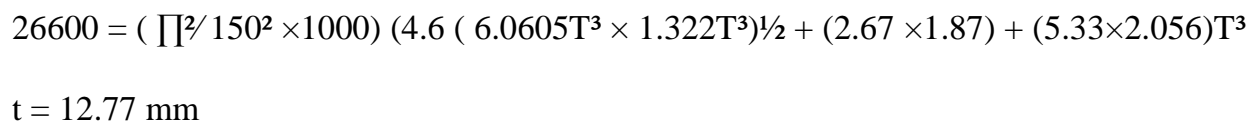

The thickness of pure composite plate $=\mathbf{t}=\mathbf{1 3} \mathrm{mm}$

\section{Stiffened Panel with Isogrid}

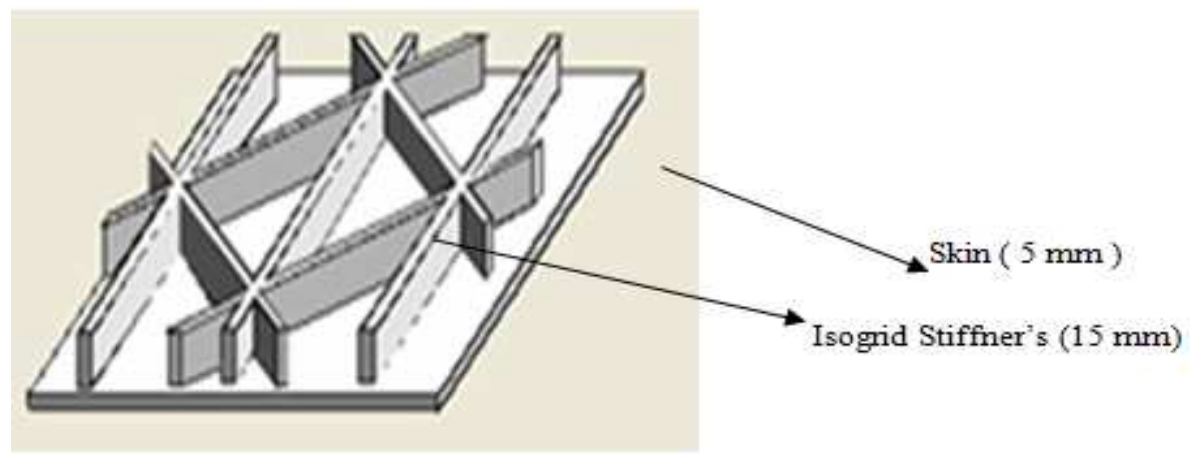

Figure2.4: Composite Plate with Isogrid Stiffner

- Dimension of composite plate with isogrid stiffner

- $\quad$ Length $=800 \mathrm{~mm}$

- Breath $=200 \mathrm{~mm}$

- $\quad$ Skin thickness $=5 \mathrm{~mm}$ 
- $\quad$ Stiffner thickness $=15 \mathrm{~mm}$

- $\quad$ Angle between stiffners $=60^{\circ}$ and $30^{\circ}$

Total numbers of layers are eleven out of which first ten layers are of skin and remaining one is of stiffner having thicknessof $15 \mathrm{~mm}$

Each layer from one to ten is of thickness $0.5 \mathrm{~mm}$

Total thickness of plate $=($ skin thickness + stiffner's thickness $)$

$$
\begin{aligned}
& =(0.5 \times 10)+15) \\
& \mathbf{T}=\mathbf{2 0} \mathbf{~ m m}
\end{aligned}
$$

\section{Stiffened Panel with Orthogrid}

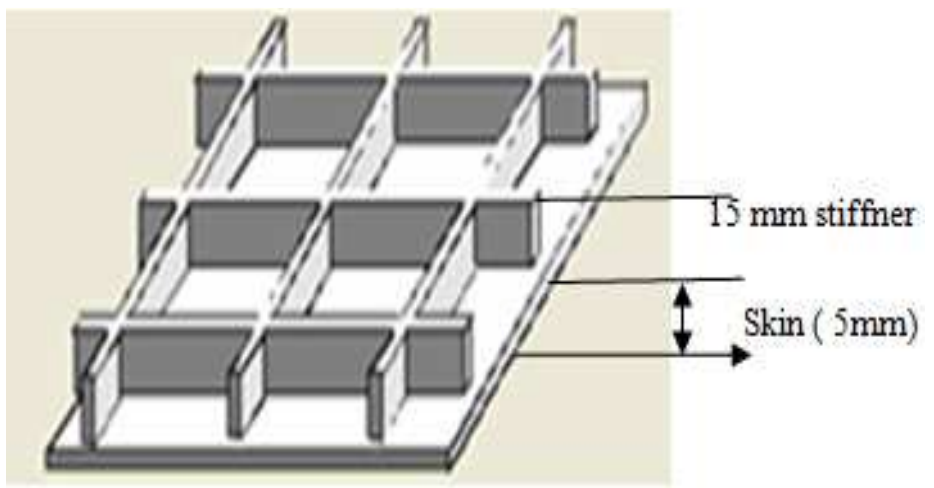

Figure2.5: Composite Plate with Orthogrid Stiffner

Dimensions of composite plate with orthogrid stiffner

Length $=800 \mathrm{~mm}$

Breath $=200 \mathrm{~mm}$

Skin thickness $=5 \mathrm{~mm}$

Stiffner height $=15 \mathrm{~mm}$

Angle between stiffner's $=0$ and 90 degree

Total numbers of layers are eleven out of which first ten layers are of skin and remaining one is of stiffener having height of $15 \mathrm{~mm}$ Each layers from one to ten is of thickness $0.5 \mathrm{~mm}$.

Total thickness of plate $=($ skin thickness + stiffner height $)$

$\mathrm{t}=(0.5 \times 10)+15)$

$\mathbf{t}=\mathbf{2 0} \mathbf{~ m m}$

\section{1: Buckling Analysis of the Fuselage Panel}

The stiffness matrix of an element $[\mathrm{K}]$ is calculated from the equation,

$\mathrm{K}=\int_{\mathrm{V}}[\mathrm{B}] \mathrm{T}[\mathrm{C}][\mathrm{B}] \mathrm{dv}$ 
Where, $[\mathrm{B}]$ is the strain-displacement matrix.

$[C]$ is constitutive matrix.

\section{Formulation of Geometric Stiffness Matrix [Kg]}

Geometric stiffness matrix can be written as

$[\mathrm{Kg}]=\int_{\mathrm{V}} \mathrm{d}[\mathrm{Bnl}] \mathrm{T}\{\sigma\} \mathrm{dv}$

Where [Bnl] is the nonlinear strain-displacement matrix, $\{\sigma\}$ is the compressive stress matrix

The global stiffness matrix of the stiffened plate finite element model is obtained by computing the element stiffness matrix of each element and assembling them by posting them in appropriate global locations determined by node numbering and connectivity.

\section{Linear Buckling Analysis}

During buckling, the total stiffness matrix becomes singular or the determinant of the total stiffness matrix vanishes.

The eigen value problem of instability is therefore formulated as $([\mathrm{Ko}]+[\mathrm{KG}])\{\delta\}=0$

$([\mathrm{Ko}]+\delta \mathrm{b}[\mathrm{Kg}])\{\delta\}=0(1.3)$

The buckling pressure is evaluated for the condition $[\mathrm{Ko}]+\lambda b[\mathrm{Kg}]=0$

Where, $\mathrm{b}$ is the non-dimensional buckling pressure.

The solution procedure adopted for obtaining the linear buckling pressure is the determinant search procedure.

A value of $\delta$ is assumed and the determinant of the matrix is calculated.

The process is repeated by Element stiffness matrix [K]:

The stiffness matrix of an element $[\mathrm{K}]$ calculated from the equation,

$K=\int_{v}[B] T[C][B] d v$ Where $[B]$ is the strain-displacement matrix. $[C]$ is constitutive matrix.

\section{Formulation of Geometric Stiffness Matrix $[\mathrm{Kg}]$}

- Geometric stiffness matrix can be derived from the expression [16] given below.

- $\quad[\mathrm{Kg}]=\int_{\mathrm{v} \mathrm{d}} \mathrm{d}[\mathrm{Bnl}] \mathrm{T}\{\sigma\} \mathrm{dv}$ Where $[\mathrm{Bnl}]$ is the nonlinear strain-displacement matrix, $\{\sigma\}$ is the compressive stress matrix

- Assembly of global stiffness matrices and application of boundary condition

- The global stiffness matrix of the stiffened plate finite element model is obtained by computing the element stiffness matrix of each shell element and assembling them by posting them in appropriate global locations determined by node numbering and connectivity.

- Linear buckling analysis During buckling the total stiffness matrix becomes singular

- The eigen value problem of instability is therefore formulated as $([\mathrm{Ko}]+[\mathrm{KG}])\{\delta\}=0(2)$ 
- $\quad([\mathrm{Ko}]+\lambda \mathrm{b}[\mathrm{Kg}])\{\delta\}=0(3)$

- $\quad$ The buckling pressure is evaluated for the condition $[\mathrm{Ko}]+\lambda \mathrm{b}[\mathrm{Kg}]=0(4)$

The finite element method has become a powerful tool for the numerical solution of a wide range of engineering problems. An assembly process, duly considering the loading solution of these equations gives us the approximate behavior of the continuum. ANSYS, Inc. is an engineering simulation software provider founded by software engineer John Swanson. It develops general-purpose finite element analysis and dynamics software. While ANSYS has developed a range of computer-aided engineering (CAE) products, it is perhaps best known for its ANSYS Mechanical and ANSYS Multi physics products.

\section{RESULTS AND DISCUSSIONS}

The buckling analysis of the Iso-grid and Ortho-grid stiffened panel structure has been performed in this work. Based on the results obtained from the FE ANSYS analysis, the Ortho-grid stiffened structure is better than the Iso-grid in terms of the load bearing capability and weight. The deformation for different materials under given loading conditions are tabulated. The deformations for the isogrid and pure composite are more than the other materials. Similarly, the frequency for different materials on the same loading and boundary conditions are shown in the in the table. The frequency for composite with isogride is lower than the frequency of other materials. The Configuration of fuselage section is shown in the Figure.4.1 and the Figure.4.2 depicts the panel taken for the analysis.
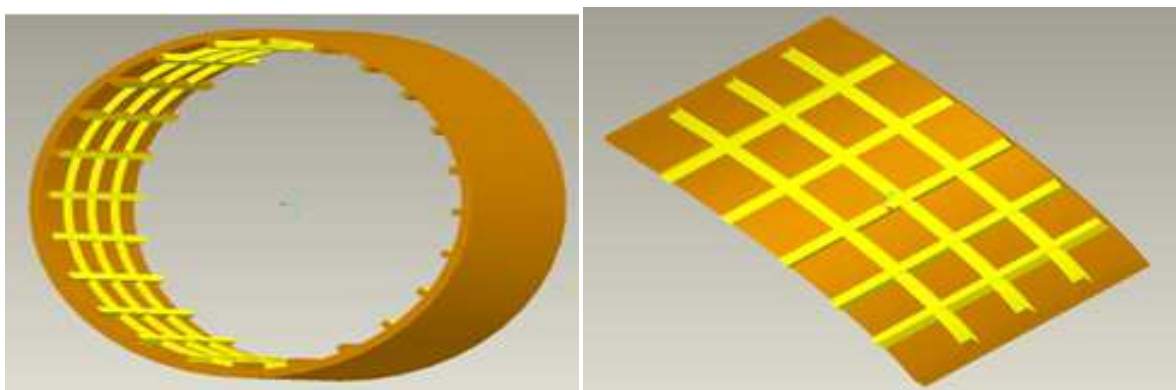

Figure.4.1: Orthogrid Fuselage Section Figure.4.2: Orthogrid Stiffened Panel
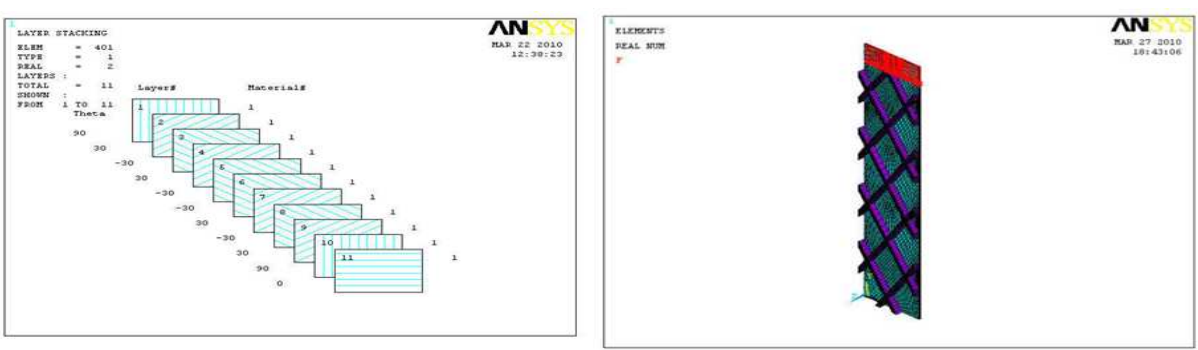

Figure 4.3: Ply Sequence at Skin Figure 4.4: Load \& Boundary Conditions 


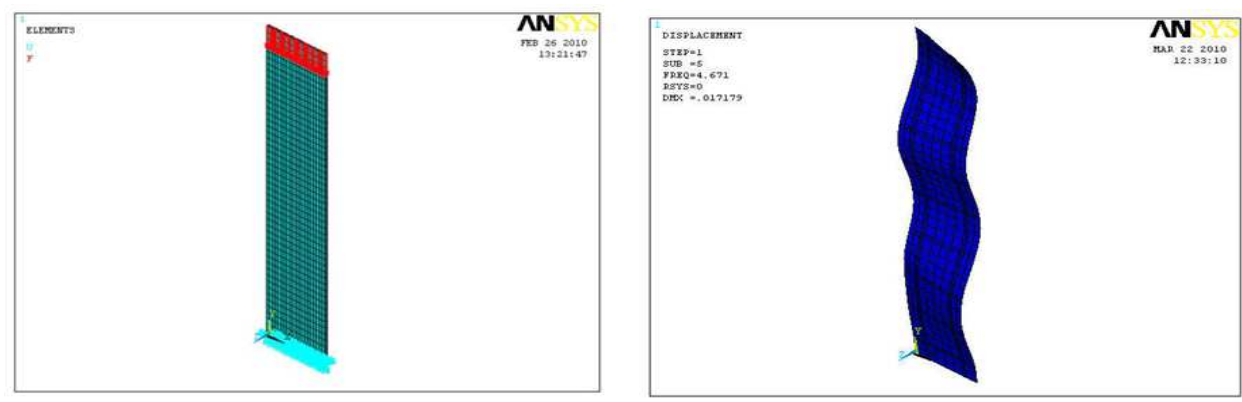

Figure 4.5: Load \& Boundary Conditions Figure 4.6: Buckling Mode Shape

Table4.1:Frequency and Deformation

\begin{tabular}{|l|c|c|c|}
\hline \multicolumn{1}{|c|}{ MATERIAL TYPE } & Load(kN) & Deformation (mm) & Frequency max (Hz) \\
\hline Isotropic(aluminium) & 2660 & 0.01403 & 6.849 \\
\hline Pure composite & 2660 & 0.024961 & 4.34 \\
\hline Composite with isogrid & 2660 & 0.021614 & 3.905 \\
\hline Composite with orthogrid & 2660 & 0.017179 & 4.671 \\
\hline
\end{tabular}

\section{CONCLUSIONS}

The stiffened panel for the fuselage has been designed and analyzed for Buckling using Ansys software. The level of deformations and frequencies observed are close to the theoretical values. However, the results of the laminate analysis and finite element analysis shows that they are within 10\%. The maximum deformation of the composite panel under given loading and boundary conditions is $0.017179 \mathrm{~mm}$, which is very less compared to other materials. The experimental results of stiffened panels for buckling response under compression loading were compared with the numerical results obtained using linear and nonlinear finite element analysis.

\section{REFERENCES}

1. Elaldi, F., Lee S., and Scott R. F., Design, Fabrication and Compression Testing of Stiffened Composite panels for Aircraft Structures, NRC LTR-ST-187, 1992.

2. Starnes J. H., Knight, F. K., Rouse M., Post-buckling of selected flat stiffened graphite epoxy panels loaded in uni-axial compression, AIAA 23(8), p.344, 1988.

3. Design and Analysis of a Composite Fuselage by Marco Aurelio Rossi, 2009 Brazilian Symposium on Aerospace Eng. \& Applications

4. K Veeranjaneyulu, MSN Gupta, Dhanajayan and Vamsi V, 2017. Damage analysis of low speedimpact on composite materials. International Journal of Civil Engineering \& Technology (IJCIET

5. G. Dhanajayan, Veeranjaneyulu kalavagunta, V. Vamshi and M. satyanarana gupta,2017. Environmental study on gfrp composite laminates international journal of civil engineering \& technology (ijciet)

6. Naveen Kumar VN et al., Analysis of Foreign Object Impact on Aircraft, International Journal of Mechanical and Production Engineering Research and Development (IJMPERD), Volume 6, Issue 2, March - April 2016, pp. 11-22

7. Dr. M SatyanarayanaGupta, Prof \& HOD K Veeranjaneyulu, Associate Professor International Conference onAdvancements in Aeromechanical Materials for Manufacturing (ICAAMM-2016International MLRIT, HyderabadJuly 9-11, 2016 Fabrication and Analysis of Adhesive joints Used in Aircraft Structures

8. K. Vijayakrishna \& P. R. Sagar., Robust Controller for Aircraft Yaw, International Journal of Electrical and Electronics 
Engineering Research (IJEEER), Volume 4, Issue 2, March - April 2014, pp. 65-70

9. Veeranjaneyulu K, KhannanTStructural Modeling And Analysis Of Composite Wing Rib Using Finite Element Method 'publication date 2015/10 Journal International Journal \&amp; Magazine of Engineering, Technology,

10. Management and Research Volume 2 Issue 5 Pages 20 PublisherIJMETMRRajagopalan, K., Finite Element Buckling Analysis of Stiffened Cylindrical Shells. Oxford and IBH PublishingCompany, New Delhi, India, 1993 